\title{
A Recusa do Tempo e suas Implicações na Subjetividade
}

The time refusal and its implication in subjectivity

Vera Lúcia Giraldez Canabrava

Universidade Federal do Rio de Janeiro

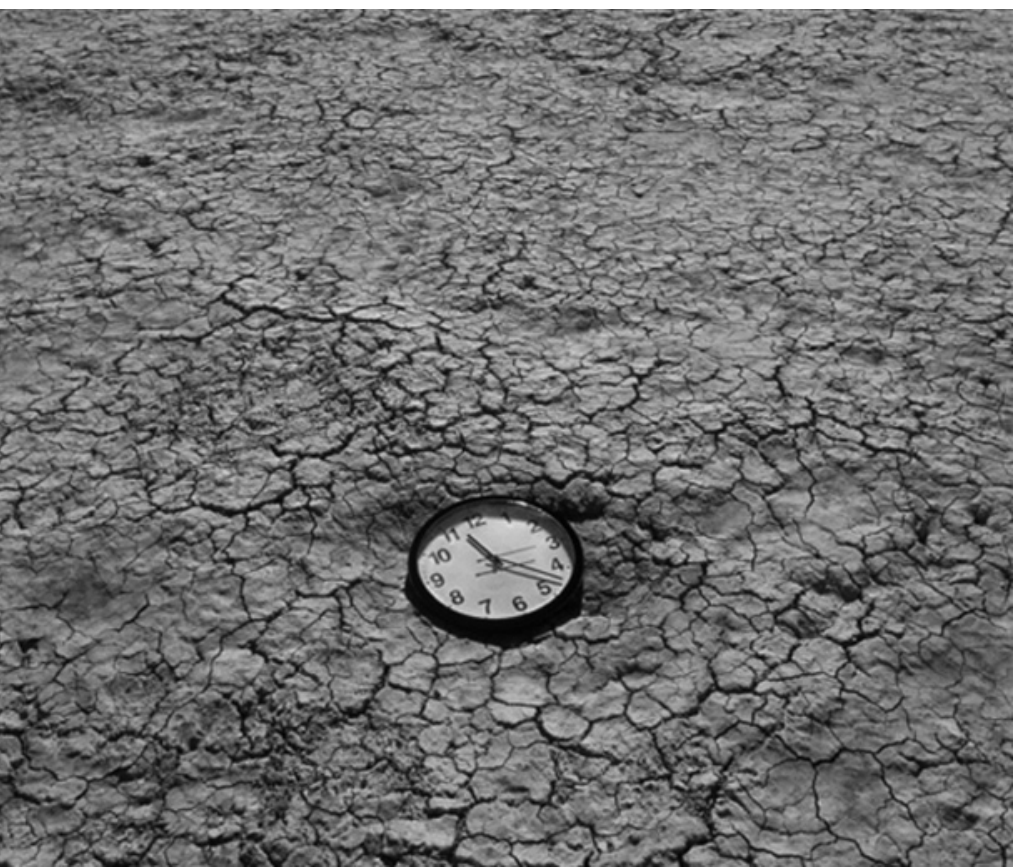


Resumo: Este artigo reflete sobre o tempo, que ainda é vivido apenas no aspecto linear, cronológico. Discorre sobre as teorias de Henri Bergson acerca da memória, de Gilles Deleuze, sobre tempo, imagem e arte cinematográfica, e das idéias de Deleuze-Guattari sobre a imagemcristal. É um estudo motivado na produção de novos modos de considerar a subjetividade e criar novas condutas nos tempos das terapias, potencializando pequenas diferenças individuais e grupais, quando da atualização do virtual, que fortaleçam a vida, liberem intensidades aprisionadas pelas formas geradas na recusa do tempo e ensejem a expressão das potências cativas, potências do tempo, que trazem à cena pontos de singularização, novos e mutantes pontos de verdade, verdades transitórias, como no cinema, que opera com diversas modalidades de imagens-tempo e privilegia imagens que emergem diretamente do tempo, em que os objetos estão dispostos em infinitos planos.

Palavras-chave: Tempo. Memória. Subjetividade. Imagem.

Abstract: This article reflects about time, that is still lived only in the linear, chronological aspect. It discusses the theories of Henri Bergson concerning memory, of Gilles Deleuze, concerning time, image and cinematographic art and Deleuze-Guattari's theory on the crystal image. It is a study motivated by the production of new ways to think about subjectivity and the creation of new behaviors in the time of therapy, highlighting small individual and group differences, when the virtual update occurs, that fortify life, liberating the intensities imprisoned by forms generated in the refusal of time, the expression of the captive powers, powers of time, that reveal points of singularization, new and mutant points of truth, transitory truth, as in the cinema, that operates with diverse kinds of time images and privileges images that emerge directly from time, where the objects are disposed in infinite plans.

Keywords: Time. Memory. Subjectivity. Image.

Todos nós sabemos que existe um tempo cronológico. O que se pretende é avaliar o quanto nos habituamos a considerar o tempo linear, cronológico, como o único existente, e o quanto a ele somos inteiramente submissos.

Quem já não repetiu esta frase: "Eu gostaria de poder, mas não tenho tempo"? E quando foi que paramos para refletir sobre nossa impotência diante do que sentimos, ao querer apressar o tempo? Mas nada podemos fazer antes da hora, a não ser aguardar no tempo, pois estamos imersos no tempo, e apenas depois do acontecido é que passamos a saber que havia um momento/tempo destinado àquele fato, um tempo para cada fato acontecer, um tempo para se entender o que nos está sendo esclarecido, o que estamos vivendo, só nos restando receber do tempo. Ao refletirmos sobre essa realidade, estamos falando dos tempos da terapia, estamos falando de vida - e de possíveis aberturas para um novo acionar da vida, que se pode dar numa atenta ótica do tempo.

Embora a ordenação linear, os acontecimentos da vida, que "são ordenados no tempo, dispostos em sua seqüência como numa fila" e que "têm seus antecedentes e suas conseqüências, (fatos), que se agrupam apertados, pisam os calcanhares uns dos outros, sem parar, e sem nenhuma lacuna" (Schulz, 1994), e, embora essa ordenação 
Há um ato que precede outro para que se realize uma ação, há um passado que antecede um presente que antecede um futuro. funcione como um quebra-cabeça que encaixa peças já dadas e seja freqüentemente entendida como o único encadeamento de temporalidade existente, trata-se de uma narrativa orgânica, apenas, que contém o relato de um eu que concorda consigo mesmo e tem uma identidade fixa. O problema do tempo se impõe se a intenção é considerar a subjetividade como algo além do enfileiramento de presentes. Há um ato que precede outro para que se realize uma ação, há um passado que antecede um presente que antecede um futuro. Mas não é isso. Vejamos o que dizem os estudiosos do assunto.

Dependendo do enfoque teórico, a memória pode ser concebida como psicológica, produzida por faculdades ativas e voluntárias do sujeito, de um eu psicológico. É, ainda, descrita como a capacidade de reconhecer imagens do tempo (tempo puro), de modo algum sujeitas ao psíquico.

Seus processos de reconhecimento, segundo Deleuze (1999), em conjugação com Bergson (1896/1990), são dois:

1. O reconhecimento automático, que tem seu fundamento na percepção e na ação, nos movimentos que prolongam a imagem-percepção na imagem-ação e que produzem uma memória dos dispositivos motores e dos hábitos.

2. O reconhecimento atento, realizado por intervenção temporal na subjetividade-afecção, através da imagem-lembrança, que constitui a subjetividade-lembrança, nesse primeiro aspecto da memória ou da lembrança pura. No segundo aspecto da memória, estará se produzindo a subjetividade-contração.
Então, temos uma memória gerada pelos dispositivos motores, aquela que nos leva à ação diante do reconhecimento de um objeto já vivenciado, daí o esquema ter sido denominado de sensório-motor. Isso evidencia uma percepção e uma memória. Automático é o reconhecimento próprio do esquema sensório-motor, em que é suficiente estarmos diante do objeto para que entrem em funcionamento os mecanismos motores já acumulados.

Em nosso cotidiano, há uma troca freqüente dos objetos; estamos sempre saindo de um para outro e prolongando a percepção em algum movimento que nos seja útil, ação que, por ser conhecida e habitual, executamos sem pensar: abrir uma porta, apertar o interruptor diante do escuro. A percepção prolongada numa ação dispensa o pensamento, pois o esquema sensório-motor reduz, ao máximo, as diferenças para dar respostas úteis, gerando-se daí uma subjetividade regida pelos interesses da percepção, que concebe o tempo pela passagem enfileirada e contínua de presentes e que considera o tempo uma decorrência do movimento (Bergson). Na medida em que somos reconduzidos ao mesmo objeto, disposto em diferentes planos, nossa atenção vai nos introduzindo nas regiões mais profundas da nossa subjetividade. Saltamos em regiões do passado porque o reconhecimento atento se dá por intervenção direta da memória de imagens-lembrança. O tempo assume nesse reconhecimento um papel preponderante: vai-se da percepção à memória, e não mais da percepção à ação, e, por isso, o papel decisivo que as imagenslembrança adquirem. A imagem-lembrança participa do reconhecimento atento, mas o tempo ainda atua como coadjuvante, descrevendo amplos circuitos, que vão das imagens-lembrança e das imagens-sonho às suas atualizações: 
É difícil pensar que o passado

é, produzindo uma narrativa não-orgânica, na qual não há linha divisória fixa, e, por isso, como na vida, existem falsos passados, múltiplos passados, presentes suspensos, diversos futuros, séries que concordam entre si, mas não com o todo.
Se a imagem retida ou rememorada não chega a cobrir todos os detalhes da imagem percebida, há um apelo lançado às regiões mais profundas e afastadas da imagem percebida, às regiões mais profundas e afastadas da memória, até que outros detalhes conhecidos venham a se projetar sobre aqueles que se ignoram. (Bergson, 1896/1990)

O objeto percebido é recriado pela imagemlembrança, na medida em que não se prolonga a percepção na ação. Com isso, produz-se um novo circuito: da percepção à memória, da percepção às imagenslembrança. A percepção vai se aprofundando, recriando com as imagens-lembrança o objeto percebido, ou, simplesmente, sobrepondo novos contornos à imagem já percebida. Quanto mais nos aprofundamos nas camadas da realidade material, mais verificamos um aprofundamento simultâneo em níveis da nossa realidade espiritual. $\mathrm{O}$ circuito criado entre a percepção e a imagem-lembrança é composto por uma série de circuitos crescentes. A imagem-lembrança se distingue da percepção pelo fato de trazer consigo a marca do passado.

\section{Memória e subjetividade}

Isso significa dizer que os dois tipos de reconhecimento implicam a distinção entre as memórias: uma memória dos dispositivos motores e dos hábitos e outra temporalizada, que, no entanto, pode implicar imagens lembrança e/ou a lembrança pura. A imagemlembrança participa da lembrança pura, que ela começa a materializar, e da percepção (Bergson). Apenas a lembrança e a contração implicam a subjetividade propriamente dita, em que as lembranças dos antigos passados se conservam em si mesmas no passado puro. A memória é "a síntese fundamental do tempo que constitui o ser do passado (o que faz passar o presente)", diz Deleuze (1988, 1999), que, retomando o primeiro capítulo de Matéria e Memória (Bergson (1896/1990), distingue cinco aspectos da subjetividade:

1. subjetividade-necessidade: que implica a retenção daquilo que interessa à vida;

2. subjetividade-cérebro: é o intervalo de hesitação para escolha da ação; 3. subjetividade-afecção: é a imobilidade própria, a não-devolução da percepção através da ação; 4. subjetividade-lembrança: primeiro aspecto da memória em que a lembrança se atualiza no intervalo; 5. subjetividade-contração: corresponde ao segundo aspecto da memória, em que o instante se contrai como um ponto.

Por estarmos demasiadamente habituados a pensar em termos de presente, de acontecimentos atuais, numa lógica linearizada e dialética, enfileiramos os fatos. Essa lógica tem dificuldade em admitir que o presente foi e que o passado não se esgota no era. Ao contrário, o passado se conserva. É difícil pensar que o passado é, produzindo uma narrativa não-orgânica, na qual não há linha divisória fixa, e, por isso, como na vida, existem falsos passados, múltiplos passados, presentes suspensos, diversos futuros, séries que concordam entre si, mas não com o todo.

A teoria bergsoniana, além de conferir ao passado a condição de fundamento do tempo e de regime temporal que, "puxando", faz passar os presentes para trás, permite que os antigos presentes se inscrevam quando já se encontram na qualidade de imagemlembrança. A teoria mantém a impossibilidade de atualização do passado puro, conferindo contornos cintilantes ao passado daquilo que já foi vivido, e acentuando, paradoxalmente, um passado que jamais foi vivido. 
As imagens-lembrança são distintas das imagens virtuais, da lembrança pura, ainda que, em ambos os casos, tanto no reconhecimento automático quanto no atento, o tempo se inscreva como protagonista, como o personagem problemático. No primeiro, inscreve-se de modo indireto, e, no segundo, de modo direto.

Este artigo aborda a ruptura do tempo linearizado. Tem como motivação uma subjetividade mergulhada na temporalidade paradoxal, que se organiza para produzir, em composição com os afetos do tempo, linhas de fuga, que se oponham às forças do constrangimento, afirmando microgestos que ensejem rupturas nos sentidos retrógrados, próprios ao tempo da sucessão, e que potencializem pequenas diferenças individuais e grupais. Adotar a diferença de natureza que existe entre o passado e o presente significa a compreensão de que percepção e memória, ao serem consideradas simultâneas, não podem implicar, entre elas, apenas uma diferença de grau, como admite o conjunto das teorias psicológicas, ou seja, compreender a memória apenas como uma gradação esmaecida do percebido, trazer à cena pontos de singularização, novos e mutantes pontos de verdade, verdades transitórias, como no cinema, que opera com diversas modalidades de imagens-tempo. A Condessa Descalça, The Barefoot Contessa (1954), filme de Joseph L. Mankiewicz, em que as imagenslembrança se misturam, buscando construir o personagem da condessa, ou $O$ ano passado em Marienbad (1960), de Alain Resnais (com roteiro de Alain-Robbe-Grilet), que emerge na subjetividade-contração, saltando nos lençóis do tempo, contraídos, quando não há coerência nas séries do tempo, em que o eu discorda de si (e quantas vezes!). O eu é um outro, que marca um desencaixe e rompe com a subjetividade escravizada por uma lógica das identidades, porque, afinal, como ordenar fatos que não possuem um "lugar no tempo, pois aconteceram tarde demais, quando todo o tempo já foi distribuído, dividido, desmontado, e que agora ficaram numa fila, não alinhados, suspensos no ar, sem lar, errantes?" (Schulz, 1994).

Esse compromisso nos leva a focalizar a distinção tanto entre a imagem-lembrança, própria à memória psicológica, formada necessariamente por antigos atuais, e a lembrança pura, própria da memória imemorial e, em conseqüência, do virtual, e, por isso mesmo, das distinções de natureza entre percepção e memória. Esses aspectos da subjetividade correspondem a duas multiplicidades: matéria e memória, percepção e lembrança, objetivo e subjetivo. Indiscutivelmente, as imagens-lembrança intervêm no reconhecimento atento e fazem surgir um outro estilo de subjetividade, acrescentando um "patrimônio imaterial" que nos leva a pensar na importância de incluir os sentidos dos acontecimentos:

Em outras palavras, enfim, as lembranças pessoais, exatamente localizadas, e cuja série desenharia o curso de nossa existência passada, constituem, reunidas, o último e maior invólucro de nossa memória. Essencialmente fugazes, elas só se materializam por acaso, seja porque uma determinação acidentalmente precisa de nossa atitude corporal as atrai, seja porque a indeterminação mesma dessa atitude deixe o campo livre ao capricho de sua manifestação. (Bergson, 1897/1990)

No entanto, se nossa pesquisa busca submergir no tempo e trazer novas imagens, faz-se necessário distinguir entre reconhecimento atento e automático, já que, no caso deste último, nós nos encontraríamos aprisionados ao nosso passado pessoal, e sujeitos não 
A estratégia de produção de subjetividade,

que pesquisamos, propõe-se a

provocar novas vias

de subjetivação, imergindo do imemorial, do

tempo desabitado de qualquer lembrança, do tempo do criar. apenas aos hábitos necessários à vida mas também a ressentimentos próprios à subjetividade-lembrança. A estratégia de produção de subjetividade, que pesquisamos, propõe-se a provocar novas vias de subjetivação, imergindo do imemorial, do tempo desabitado de qualquer lembrança, do tempo do criar.

\section{Imagem-cristal / lembrança pura}

Nos pequenos circuitos, não há mais a dilatação, e sim, a contração das imagens até um ponto de indiscernibilidade entre elas, simultaneamente presentes e passadas. A imagem atual e sua imagem virtual coexistem, imagem bifacial, imagem coalescente, cristal do tempo, na qual percepção e memória coincidem. No circuito pequeno, opera-se uma mudança de natureza.

Nos amplos circuitos, são próprios os movimentos extensivos, e, nos pequenos circuitos, são próprios os movimentos intensivos, constituindo-se a indiscernibilidade entre atual e virtual, percepção e memória. Reside aí, nessa coincidência, a originalidade da concepção da memória em Henri Bergson.

A imagem coalescente, para Félix Guattari, adquire as feições de imagem-cristal ou ritornelos do tempo, belissimamente apresentadas, especialmente quando dos ritornelos proustianos em $O$ Inconsciente Maquínico (1988).

A imagem-cristal é retomada por Gilles Deleuze (1990), em Imagem Tempo, como os cristais do tempo, em que o filósofo nos possibilita intuir uma subjetividade cristalina. Os conceitos de Bergson, Guattari e Deleuze já não se distinguem mais, perdem-se os nomes próprios nesse mergulho no tempo puro:
É, por sob esses cristais bem recortados e esse congelamento superficial, uma continuidade que se escoa diferente de tudo que já vi escoar-se. É uma sucessão de estados em que cada um anuncia aquele que o segue e contém o que precedeu. A bem dizer, eles só constituem estados múltiplos quando, uma vez tendo-os ultrapassado, me volto para observar-lhes os traços. Enquanto os experimentava, eles estavam tão solidamente organizados, tão profundamente animados com uma vida comum, que eu não teria podido dizer onde qualquer um deles termina, onde começa o outro. Na realidade, nenhum deles acaba ou começa, mas todos se prolongam uns nos outros. (Bergson, 1907/1979)

Na imagem-cristal, nesses mínimos circuitos, a reversibilidade não apenas é permanente, mas é também o "elemento genético" que expressa a subjetividade-cristalina, que estamos pesquisando, na medida em que as contínuas mutabilidades entre atual e virtual não são produtos da memória psicológica. São duplas por natureza, e, por isso mesmo, indiscerníveis, aspecto que iremos observar no filme de Orson Welles, Cidadão Kane (1941), em que ocorre a operação fundamental do tempo, cisão em que o presente se lança simultaneamente em direções heterogêneas para o passado e o futuro, o que se mostra na imagem-cristal, nos pequenos circuitos bergsonianos, na memória-contração, na lembrança pura.

Mas o que podemos dizer da lembrança não rememorada, a virtualidade?

Se há distinção entre a imagem-percepção e a imagem-lembrança, também existe diferença entre a imagem-lembrança e a lembrança pura. A lembrança pura é apenas virtual. A imagem-lembrança e a lembrança pura são diferentes em natureza, porque esta última jamais foi presente. 
A imagem virtual é denominada, por Bergson, de lembrança pura, com o intuito de distingui-la das imagens mentais, das imagenslembrança, imagens-sonho, que são também imagens temporalizadas:

A imagem (lembrança pura) não é um estado psicológico ou uma consciência: ela existe fora da consciência, no tempo, e não deveríamos ter mais dificuldades para admitir a insistência virtual de lembranças puras no tempo do que a existência atual de objetos não percebidos no espaço. (1897/1990, p. 100)

Trata-se de pesquisar os longos e os pequenos circuitos, pois é justamente neles, no intervalo, conforme Bergson, que se opera a positividade da intervenção do tempo na afecção. Nos primeiros, uma subjetividade-recordação, e, nos segundos, uma subjetividade-contração.

Éjusto aí que se concentram nossas motivações: nas transformações da inscrição do tempo na subjetividade - de uma subjetividade regida pela imagem-lembrança, subjetividade psicológica, para subjetividades-contração, inacabadas e intensivas, cristalinas - onde o tempo, através da imagem-cristal, se inscreve, abandonando sua posição de ator coadjuvante e transformando-se no personagem principal.

O tempo psicológico seria, nessa hipótese de pesquisa, apenas um caso particular do tempo paradoxal.

Mas, se nosso passado permanece quase inteiramente oculto para nós, é porque é inibido pelas necessidades da ação presente, e irá recuperar a força de transpor o limiar da consciência sempre que nos desinteressarmos da ação eficaz para nos recolocarmos, de algum modo, na vida do sonho. (Bergson, 1897/1990)
O conhecido fenômeno do déjà vu exibe, conforme Bergson, a coexistência entre o presente e seu passado contemporâneo, entre a percepção e a memória, num dos paradoxos do tempo, que seu modo de pensar vai engendrando: o presente foi, o passado é.

A memória, contraída em mínimos circuitos, em que passado e presente são simultâneos, compõe a imagem-cristal, abrindo a possibilidade da inscrição do tempo jamais vécu. Inscrever-se-ia, nesse ponto, na subjetividade, um tempo imemorial?

O ser entendido como imerso no tempo distribui-se em corpos atuais e incorporais virtuais, a partir da imagem-cristal. Esta se delineia nos pequenos circuitos, através dos quais os tempos se complicam. Se, por um lado, as imagens-lembrança e as imagenssonho implicam um circuito amplo que as une às imagens atuais, e no qual as imagens atuais e virtuais são discerníveis, por outro, tratar-se-á de pesquisar os menores circuitos, não mais a dilatação da memória, mas a sua contração até um ponto de indiscernibilidade entre a imagem atual e sua imagem virtual, imagem bifacial, imagem mútua, cristais do tempo.

No pequeno circuito, operam-se as distinções de natureza, não de grau. Conforme Bergson (1897/1990), são aquelas que se dão nas problematizações do tempo e não do espaço, de onde estaríamos concebendo intensidades, o passado virtual não psicológico, um passado imemorial. As diferenças de grau são aquelas que se dão na extensão ou no modo de pensar do bom senso, que supõe o passado como apenas decorrente do presente vivido.

Se nosso objeto de pesquisa opera na ruptura do tempo da sucessão, importar-nos pesquisar a inscrição do tempo puro e admitir a contração e a coexistência. Na medida em 
O que Bergson mostra é que esse modo de pensar decorre de uma concepção do tempo como sucessão. que se estabelece a tese da coexistência virtual do passado, trata-se de níveis do passado, todos coexistentes, incluindo cada um deles a totalidade do ser e diferindo exclusivamente por seu grau de contração:

O que é que se vê no cristal?

O que se vê no cristal é o tempo não cronológico.

...O cristal ou a imagem-cristal não é apenas óptica... o cristal tem também propriedades acústicas, a imagem-cristal é também sonora.

...Todo cristal revela o tempo... A noção de cristal me parece tão rica...

(Deleuze, 1990)

No fenômeno por todos nós já vivenciado, o déjà vu, poderemos observar as distinções de natureza e de grau. Usualmente, temos a impressão de estar revivendo, no presente, algo vivido no passado. Nesse modo de pensar, a memória é considerada decorrente daquilo que já foi percebido: a memória seria uma percepção esmaecida. Tratar-se-ia de uma diferença de grau.

O que Bergson mostra é que esse modo de pensar decorre de uma concepção do tempo como sucessão. O déjà vu, na concepção bergsoniana, evidencia a simultaneidade do presente e do passado, da percepção e da memória, breve instante, privilegiado instante, em que o tempo mostra seu passar bifurcante, distribuindo-se em atual e virtual. Podemos dizer ainda que é da natureza do tempo o ocultar-se, e que o déjà vu expressa, em especial, a imagem mútua, os cristais do tempo:

É preciso que o tempo se cinda ao mesmo tempo em que se afirma ou desenrola: ele se cinde em dois jatos dissimétricos, um, fazendo passar todo o presente, e o outro, conservando todo o passado. $\mathrm{O}$ tempo consiste nessa cisão, e é ela, é ele que se vê no cristal. A imagem-cristal não é o tempo, mas vemos o tempo no cristal.
Vemos a perpétua fundação do tempo, o tempo não cronológico dentro do cristal. (Deleuze, 1990)

Não seria dessa invisibilidade do tempo que Ulisses Pereira Chaves, artista do Vale do Jequitinhonha, diz, com simplicidade e sabedoria, referindo-se às peças de barro que produz: "As peças estão invisíveis na minha frente, eu só faço passar para o barro".

\section{Lençóis do tempo e pontas do presente}

De modo distinto das imagens, que estão em movimento e que implicam possibilidade de resolução, as imagens-tempo apresentamse como problemas, pois é da natureza do tempo apresentar-se sob dupla configuração: no cristal, o tempo se apresenta ora no presente ora no passado. Sendo, pois, próprio à imagem cristalina, o tempo apresenta-se simultaneamente como passado e presente, havendo troca incessante entre o atual e o virtual. Podemos dizer que é da natureza da imagem-cristal ser germinativa.

Na perspectiva do presente, do atual, todo passado é um antigo presente, e todo futuro é um presente antecipado, ou seja, aquilo que se mostra na perspectiva do presente ou é um presente antigo ou um futuro antecipado. $\mathrm{O}$ problema emerge quando o antigo presente, o passado, não pode ser evocado em função de nenhum presente e quando o futuro não pode ser expresso através de nenhum presente antecipado.

Se há um passado que não pode ser evocado, seja porque, ao ser lembrado, não pertença a nenhum antigo presente, seja porque somos incapazes de evocá-lo, então o passado não se confunde mais com um antigo presente. Por outro lado, o presente, enquanto futuro antecipado, se desfaz por aquilo que não pode ser antecipado, por aquilo que não se 
A descrição cristalina, de outro modo, não existe fora do próprio mundo que a constrói, por isso é um cristal do tempo: "Se o tempo aparece diretamente, é nas pontas de presente desatualizadas, é nos lençóis do tempo virtual" (Deleuze, 1990). configura em nenhuma antecipação possível. Assim se mostram as pontas do presente em O Ano Passado em Marienbad, que evidencia a impossibilidade de comunicação dos personagens imersos em pontas tanto do presente quanto do passado e do futuro.

Esses problemas revelam a impossibilidade de se reduzir qualquer passado ou futuro ao presente, o que garantiria a identidade do eu estrutural, porque a integridade de um eu não permite que haja algo não seqüencial e tampouco um acontecimento não antecipável, que não se submete a ser efeito-causa de um fato determinante, na medida em que somos hoje o mesmo que seremos amanhã, e, portanto, tudo estaria na espera de um presente que se alargaria sem obstáculos, ou ainda, que venceria permanentemente os obstáculos para permanecer sendo o que é, ou seja, plenamente previsível: o amanhã não seria senão o futuro antecipado.

No caso do tempo que atravessa o cristal, há esse devir outro, que torna o futuro impossível de ser antecipável. Então, remeternos-emos ao tempo, não como uma sucessão de presentes, mas ao tempo na ordem desse puro passado que coexiste como coalescente ao presente, ao modo da coalescência entre atual e virtual, e que respeita outra postulação: todo antigo presente se conserva no tempo e é contemporâneo ao presente. Desse ponto de vista, o passado não está em outra dimensão, mas coexiste com o próprio presente, que, nessa ordem do tempo, apreende simultaneamente algo com presente (atual) e passado puro (virtual). Mas, na ordem do passado puro, em primeiro lugar, o presente é o que não é, só o passado é, só existe o ser do passado que não cessa de ser enquanto o presente não pára de passar.
Na perspectiva do tempo puro, do puro passado, o que não é é o presente. O presente não é senão um certo grau desse passado puro. Mas o passado puro, enquanto tal, é o que não se atualiza de nenhuma forma. Nessa perspectiva do passado puro, o futuro só pode existir na descoberta do próprio passado puro como invenção, como algo novo que não tinha sido ainda visto ou apreendido, o que faz novamente que não se possa colocar na ordem do passado. O tempo não poderá ser nem presente nem passado, o que leva a um rompimento entre atual e virtual enquanto híbrido, mas que restaura a possibilidade de penetração no tempo, que, por um lado, é um presente inatual, e, por outro, um passado que é um lençol, o passado como lençol do tempo, que é explorado ao mesmo tempo em que nos movimentamos.

Para pensar sobre o tempo em termos de atual/virtual, é necessário compreendê-lo através de um cinema que explora presentes inatuais e lençóis do passado. Na perspectiva destes últimos, não há mais possibilidade de operar com o verdadeiro e o falso. Todas as compreensões se tornam cristalinas, e as descrições serão cristalinas e não orgânicas. As descrições orgânicas se referem ao mundo criado por um sujeito e seus objetos. A narração orgânica não pára de distinguir, ao cindir-se entre real e imaginário. A descrição cristalina, de outro modo, não existe fora do próprio mundo que a constrói, por isso é um cristal do tempo: "Se o tempo aparece diretamente, é nas pontas de presente desatualizadas, é nos lençóis do tempo virtual" (Deleuze, 1990).

Trata-se de investir no tempo como evocador da narrativa não-orgânica, investindo no cristal, nos movimentos da câmera e nos planosseqüência, nas oscilações da imagem entre os tempos, na distância e no movimento, como alguma coisa que se dá simultaneamente, 
quando o todo se aprofunda e a distância se torna cada vez mais temporal, como em O lluminado, The Shining (1980), de Stanley Kubrick, em que as conexões temporais adquirem ligações inusitadas; emergem lençóis do passado que guardam uma certa idade, marcando os sentimentos do personagem que se movimenta num presente perturbado. É um tempo não evolutivo, porque não guarda distâncias evolutivas usuais. Trata-se de avaliar o tempo pelo jogo das imagens-pensamento, regidas pelas imagens do tempo paradoxal, em que o passado não é algo que precise ser focalizado, porque as modificações vêm dos lençóis do tempo, que emergem do fundo de um cérebro considerado pré-individual, isto é, como aquele que se compõe de infinitas conexões virtuais.

Nessa subjetividade produzida por membranas temporalizadas (Simondon), o dentro é o passado, e o fora, o futuro. A criação explode entre tempos. As pontas de presente inscrevem a realidade nos lençóis do passado, forçando a criação. A memória funciona como membrana, em que os tempos coexistem, em que o hotel de O lluminado funciona como um duplo da memória. Tratase de uma repetição protegida em que o presente não sofre passagem, é a memória do hotel que se atualiza de modos distintos.

E o cinema se expande em imagens inusitadas. Em Laranja Mecânica, A Clockwork Orange (1971), de Stanley Kubrick, o personagem, Alex, é atingido por dentro (pelos lençóis) e por fora (pela lei), mas, nesse tempo paradoxal, não há autonomia do passado nem do presente, e tampouco qualquer possibilidade de explicações, ou ainda em A Dama de Xangai, The Lady from Shangai, (1947), de Orson Welles, em que o personagem está envolvido em três lençóis do passado. Os lençóis do passado remetem a uma psicologia, mas não se esgotam aí, pois a coexistência nos força a considerar o tempo como o fora, a externalidade, o deserto, independentemente de qualquer um.

Assim como os ventos nos envolvem à nossa revelia, o tempo nos atravessa. O cinemapensamento, cinema da imagem-tempo, é marcado pela dupla inscrição dos lençóis do passado e das pontas do tempo, num confronto entre camadas do tempo, que trazem turbulências ameaçadoras para os personagens: é o necessário jogo no tempo, que remexe os lençóis do passado, revelando modos de sentir e idades que dizem de afetividades e emoções que, na imagemcristal, não seguem a ordem cronológica, porque o tempo impõe, ao pensamento, a coexistência.

No plano seqüência, os lençóis do passado aprofundam-se nos plongées e contraplongées, como zonas de exploração temporal. No cinema, o plano-seqüência corresponde ao passado, e o corte irracional do passado permite que os vínculos não sejam contíguos e se mostrem como a massa do padeiro, citada por Deleuze (1990), uma matéria plástica, ou, ainda, uma matéria afetiva, matéria imaterial, dessubstancializada. O tempo que emerge nesse cinema-pensamento através da imagem cristal abdica da presença.

A imagem-tempo articula modificações como os labirintos e os corredores de O lluminado quando os pesadelos misturam a mente e o hotel, criando uma memória única através da junção do passado do personagem alcoólatra (do ator Jack Nicholson) e dos lençóis do passado, que vão levando o presente ao desaparecimento, ao mesmo tempo em que vão trazendo a virtualidade: o passado desse 
personagem vai impregnando o hotel, que vai se transformando num mapa afetivo, mapa de acontecimentos que afetam os personagens.

O cristal reflete a imagem em todas as suas faces e projeta a imagem em todas as dimensões, produzindo uma narrativa não orgânica. O cinema da narrativa orgânica, no entanto, procede a partir de uma face exclusiva, e, nesse sentido, ela se opõe à imagem não-orgânica, centra o mundo nela mesma, como uma imagem especial, como um centro de operações, a partir de tarefas e necessidades que deve cumprir. A partir daí, o organismo efetua sua função para continuar existindo, isto é, o ser orgânico é um centro de sobrevivência.

A imagem-cristal quebra a possibilidade desse centramento, não trabalha mais no encadeamento de imagens, que se sucedem numa lógica do tempo linear, mas operam com paralisações, desencadeamentos, tateamentos. Não havendo mais a realidade orgânica, a imagem oscila em sua paradoxalidade, em sua ponta mais contraída, que lhe dá lugar no presente, e em sua dilatação plena na virtualidade. $\mathrm{O}$ presente é sempre a ponta mais contraída de uma imagem dentro de uma operação, enquanto o passado é o dilatado, e, por isso, o evocável.

Quando se trabalha com o tempo, com o condutor da narrativa, basta criar pontas do presente e retirar delas a atualidade. É como apreender a atualidade desatualizada, desnaturalizada das necessidades orgânicas, quando, então, todo movimento perde a importância. Ao presente inatual, não importa quanta movimentação tenha, não há nada a fazer, porque tudo já foi feito; ele é o que foi, e as ações aparecem como já perdidas, num já tempo perdido, inevocável: o presente em sua queda, em sua sucessão não evocável. Por outro lado, o virtual, na medida em que é apreendido nos planos-seqüência longos, não é apenas aquilo que se apresenta como o imemorável, o puro virtual, mas é também aquele que guarda algo diferente de si próprio e que esconde a própria lembrança que evoca. O cristal esconde.

\section{Considerações sobre as imagens cinematográficas}

Deleuze (1992) afirma que há vínculo entre cinema e pensamento. Do ponto de vista desse filósofo, o cinema pode trabalhar com as imagens-ação (em que a inscrição do tempo é secundária, isto é, o tempo está subordinado ao movimento), e com as imagens-pulsão (em que o tempo começa a libertar-se do movimento). Mas o cinema pode ainda ligar-se a um pensamento arriscado, singular, expressando o tempo através de imagens diretas do tempo, ora os presentes, passando sem cessar as pontas do presente, ora o passado, conservando-se, criando os lençóis do tempo. Mas, num caso e no outro, tratarse-á das imagens-cristal.

Encontramos no cinema um forte aliado para discutir a imersão da subjetividade no tempo e a passagem da subjetividade-lembrança, subjetividade psicológica, própria das imagenslembrança, à subjetividade imemorial própria da subjetividade contração. A subjetividade passa a ser tida como o problema germinativo, e o cinema, como expressão.

É interessante notar que as obras de Bergson, com as quais estamos trabalhando, foram escritas nos primórdios do cinema: Matéria e Memória, em 1897, e Evolução Criadora, em 1907. Deleuze (1990) observa que, em seus primórdios, o cinema buscava imitar a percepção natural: a câmera era fixa, o plano, espacial, os cortes, móveis, 
No cinema, em seus primórdios, passamos da câmera fixa à móvel, como nos filmes de Dziga Vertov, em que a câmera é móvel, mas a imagem começa a flutuar nas tomadas de cena, anunciando as ondulações provocadas pelo tempo, ainda que suas imagens não sejam consideradas imagens-tempo. e sua independência foi paulatinamente conquistada quando a câmera móvel se emancipou do projetor, com a criação da montagem e dos cortes móveis. E escreve que Bergson pressentia, em Matéria e Memória, os cortes móveis e os planos temporais, como se tivesse um olhar profético para os desdobramentos que iriam acontecer na arte cinematográfica.

No cinema, em seus primórdios, passamos da câmera fixa à móvel, como nos filmes de Dziga Vertov, em que a câmera é móvel, mas a imagem começa a flutuar nas tomadas de cena, anunciando as ondulações provocadas pelo tempo, ainda que suas imagens não sejam consideradas imagens-tempo. Por isso mesmo, será esse o nosso primeiro diretor ao analisarmos as condutas temporalizadas nas imagens cinematográficas.

A partir do século XIX, o tempo orgânico apresenta-se como modo de pensar a vida, voltada para o homem: pensar no domínio do desejo e da ação. Mas a vida não poderia ir além do orgânico, das funções do corpo? Estaríamos fadados aos limites dos possíveis, das causas e conseqüências encadeadas e do amanhã já determinado?

O cinema ficcional, através de distintas imagens do tempo, desfaz as fronteiras rígidas e hegemônicas do tempo linear e produz entre o imaginário e o real, entre o falso e o verdadeiro, entre o passado e o presente, como em Roma, Cidade Aberta (1945), de Frederico Fellini, quando o sensório-motor não dá mais conta das narrativas desconcertantes com as quais a vida nos envolve, e surgem personagens deambulantes, tateantes. Na ação, na relação, há vínculo sensóriomotor, mas, quando da ruptura do vínculosensório motor, começam a surgir situações flutuantes, sem contornos fixos, bem como a ascensão de ligações frágeis, não muito bem determinadas, sob a forma de perambulação, tateamentos, como algo que torna impossível formarem-se personagens de contornos nítidos, quando ocorre o rompimento dos clichês e da banalidade.

Um dos filmes do diretor francês Alain Resnais, Providence (1977), pode ser considerado um desses momentos, em que o cinema mostra o pensamento da complexidade: histórias pessoais mesclam-se aos pensamentos do personagem principal, interpretado por John Gielgud, que contracena com Dick Bogarde, num roteiro estranho e intrigante de David Warn, em que os lençóis do passado não cessam de se emaranhar. Mas, o que dizer de Marienbad (1960), dirigido também por Resnais, com um roteiro absolutamente temporalizado, realizado por Alain- RobbeGrillet, em que os tempos se mostram superpostos, múltiplas pontas de presentes? Resnais talvez tenha sido, dos diretores de cinema, aquele que mais tenha pesquisado a memória desse tempo imemorial, abrindo-a para as distintas memórias: dos personagens, dos coletivos e do mundo, chegando mesmo a misturá-las como se fossem lençóis do passado:

Em suma, a confrontação dos lençóis de passado se faz diretamente, cada um podendo servir de presente relativo ao outro: Hiroshima será para a mulher o presente de Nevers, mas Nevers será para o homem o presente de Hiroshima. Resnais começou com uma memória coletiva, a dos campos de concentração nazistas, a de Guernica, a da Biblioteca Nacional. Mas descobre o paradoxo de uma memória a dois, de uma memória de várias pessoas: os diferentes níveis de passado já não remetem a uma personagem, a uma família ou a um mesmo grupo, mas a personagens completamente diferentes, como a lugares não comuns, que compõem uma memória mundial. Ele cede a uma relatividade generalizada, e vai até o fim do que em Welles era tão-só uma direção: construir alternativas indecidíveis entre lençóis de passado. (Deleuze, 1990) 
Deslizamentos nas condutas do pensamento

Foucault (1990) escreveu que "existem momentos na vida em que a questão de saber se se pode pensar diferentemente do que se pensa, e perceber diferentemente do que se vê, é indispensável para se continuar a olhar ou a refletir". É bastante possível! Acentuou-se a transformação ocorrida tanto nos modos de pensar na ciência quanto na filosofia entre o pensamento clássico e o contemporâneo, tendo como eixo primordial os modos de conceber o tempo em suas conexões com as produções da memória e do pensamento, adotadas aqui como primordiais ao se considerar a subjetividade.

Escolhemos o cinema, que não se "move" no tempo métrico, mas explora tempos e espaços impossíveis, para nosso "estudo de caso", no intuito de, através dele, ver emergir do tempo a subjetividade, em especial, a subjetividade enquanto memória, pensamento e arte, uma subjetividade cristalina.

Em prefácio conciso, Deleuze pontua que o autor de Tempos Capitais (Alliez, 1991) "não

No cinema, essas imagenslembrança e imagens-sonho mostram-se claramente; podemos distingui-las indo do presente para o passado, descrevendo, entretanto, amplo circuito. se propõe expor concepções do tempo nem tampouco analisar estruturas temporais". Deleuze pontua que o autor se refere ao pensamento como a "condutas do tempo", o pensamento como aquilo que tem a possibilidade de "apreender o tempo através de diversos andamentos que compõem condutas".

Por vezes, aos saltos, aceitando a inspiração poética que a física contemporânea pode evocar, temos dançado em alguns andamentos do tempo, incertos e inquietantes ritmos do tempo, insistindo em envolver essa pesquisa em novas condutas no tempo, que se afastem do tempo como número do movimento extensivo, tempo das marchas e dos espaços marcados e deslizem para o tempo como produtor de movimentos intensivos emergidos da conduta de tempos aberrantes, que a arte expressa nos sons da voz de Meredith Monk. O mesmo ocorre no cinema de pensamento, estranho e arriscado, como o do diretor David Lynch, em Mulholland Drive (2001), ou de Alain Resnais, já em Providence (1977), ou ainda em Mama Roma (1962), de Pier Paolo Pasolini, que traz um empirismo herege, em que as descrições não preexistem ao deambular da câmera, que opera com o falso raccord, o falso encadeamento que nos leva a movimentos, a tempos paradoxais e "mixados".

Nas ruínas do cinema sensório-motor, está a imagem-ação, que lida com a narração orgânica e as relações em que o tempo é encadeado num todo aberto, que poderá ser totalizado e estabelecer um fim; mas, no cinema-tempo, há uma impossibilidade de totalização, um todo impossível de se fechar, porque algo de fora está sempre chegando, suscitando o "inacabamento", como em Mama Roma, em que o tempo sempre produz o acontecimento que nos envolve.

No cinema, essas imagens-lembrança e imagens-sonho mostram-se claramente; podemos distingui-las indo do presente para o passado, descrevendo, entretanto, amplo circuito. O flashback, como imagem cinematográfica, pode ser considerado como o momento de clareza das imagenslembrança, mostrando com evidência que é o tempo, e não o espaço, que se bifurca.

Desde A Condessa Descalça, rico em flashback, em que a fala do personagem Harry Dawes (ator Humphrey Bogart), referindo-se à vida da condessa Torlato-Favrini (atriz Ava Gardner), afirma a força do tempo: "O destino... ou uma força...escreveram e dirigiram sua vida", até Cães de Aluguel (1992), de Quentin Tarantino, 
a construção de imagens do tempo não cessa de modificar seus modos de expressar as mudanças na quebra do tempo linear. Tarantino cria até mesmo um flashback, se é que podemos ainda assim dizer, do que não aconteceu: Mr. Orange (personagem do ator Tim Roth) conta seu suposto encontro com policiais e o cão farejador, num banheiro de bar; através de uma imagem-lembrança evocada, ele criou um falso passado.

Como na canção "Todo sentimento", de Chico Buarque: "Prefiro então partir/ a tempo de poder/ a gente se desvencilhar da gente/ (...)/ te encontro com certeza/ talvez num tempo da delicadeza", tempo labiríntico, quando encontros impossíveis ocorrem, sem discursos, e permitem o esquecimento, tempo do encantamento, tempo dos encantados, tempo oportuno, o tempo grego do Kairós, que nos permite ir ao seu encontro e surfar no pensamento e na afetividade, longe do atavismo sentimentalista.

Tem sido esse o desafio de nossas reflexões, que buscam construir uma memória estratégica para que, ao ir além das conveniências e limitações pessoais, a memória do imemorial se abra através das imagens-tempo e possa constituir uma alternativa aos dilemas éticos e ao desespero humano, diante de um tempo que, posto na transcendência, assassinou as possibilidades da intuição do tempo dos encantados, dos poetas. Trabalhamos no sentido de ensejar subjetividades cristalinas e atmosféricas, como a pintura de Turner, na qual as singularidades impossibilitam os aprisionamentos e possibilitam a gentileza e a potência, e permitem considerar a subjetividade algo além do enfileiramento de presentes.

\section{Vera Lúcia Giraldez Canabrava}

Círculo Psicanalítico do Rio de Janeiro, psicanalista, professora, Doutora.

\section{Endereço para correspondência:}

Rua Marlo da Costa Sousa, 185, ap.1103, Bloco 1. Barra da Tijuca, Cep: 22790-735 - Rio de Janeiro-RJ. E-mail: vl.canabrava@uol.com.br

Recebido 02/04/2007 Reformulado 04/09/2007 Aprovado 10/09/2007

Alliez, E. (1991). Tempos capitais. São Paulo: Siciliano.

Alliez, E. (2000). Gilles Deleuze: uma vida filosófica. São Paulo: 34.

Bergson, H. (1979). A evolução criadora. Rio de Janeiro: Zahar. (Trabalho original publicado em 1907)

Bergson, H. (1990). Matéria e memória. São Paulo: Martins Fontes. (Trabalho original publicado em 1897)

Deleuze, G. (1974). Lógica do sentido. São Paulo: Perspectiva.

Deleuze, G. (1985). Cinema I. Imagem-movimento. São Paulo: Brasiliense.

Deleuze, G. (1987). Proust e os signos. Rio de Janeiro: Forense Universitária.

Deleuze, G. (1988). Diferença e repetição. Rio de Janeiro: Graal.
Deleuze, G. (1990). Cinema II. Imagem-tempo. São Paulo: Brasiliense.

Deleuze, G. (1992). Conversações. São Paulo: 34.

Deleuze, G. (1999). Bergsonismo. São Paulo: 34.

Deleuze, G., \& Guattari, F. (1997). Mil platôs: capitalismo e esquizofrenia (Vol. 5, P. Pál Pelbart \& J. Caiafa, trads.). São Paulo: 34 .

Foucault, M. (1990). História da sexualidade II. O uso dos prazeres. Rio de Janeiro: Graal.

Foucault, M. (1991). Vigiar e punir: nascimento da prisão (9a ed.). Petrópolis, RJ: Vozes.

Schulz, B. (1994). Sanatório. Rio de Janeiro: Imago. 